\title{
ONLINE EDUCATION TODAY
}

\author{
A. Frank Mayadas
}

John Bourne

Paul Bacsich

Online education is established, growing, and here to stay. It is creating new opportunities for students and also for faculty, regulators of education, and the educational institutions themselves. Much of what is being learned by the practitioners will flow into the large numbers of blended courses that will be developed and delivered on most campuses. Some of what is being learned will certainly improve pedagogical approaches and possibly affect other important problems, such as the lengthening time to completion of a degree. Online education is already providing better access to education for many, and many more will benefit from this increased access in the coming years.

In a 1995 Science article, Eli Noam of Columbia University opined that the Internet would pave a difficult road ahead for traditional academic institutions; he wrote, "as one connects in new ways [the Internet], one also disconnects the old ways" [1]. Thirteen years after Noam's article and 15 or so years after Internet usage began its rapid acceleration, online learning has become an important element in education, although it is not evenly distributed across institutions.

The term "online learning," however, obscures vast differences in methods supported by this educational approach. We limit this discussion to online education in traditional, regionally accredited, degreegranting institutions. Within this discussion, we include "blended courses," that is, those that feature some online elements but less face-to-face time than encountered in an equivalent traditional course. We do not discuss online education in the rapidly developing kindergarten through grade 12 environment, online corporate training, or the free educational resources (complete courses in many cases) being made available online by some universities, such as the Massachusetts Institute of Technology (MIT), Yale, Stanford, and a few others [2]. These are widely accessed throughout the world but do not provide credit as courses or as partial fulfillment toward degree completion. These efforts can thus be thought of as use of the Internet to disseminate, free of charge, valuable, high-quality information, but not credentials, whereas the focus of this paper is on use of the Internet to provide access to educational credentials through use of the common tuition and fee mechanisms.

Generally, in corporate training, online learning means accessing short training modules that cover specific topics (e.g., quality practices, new product information, and diversity practices) available as selfstudy units on the corporate intranet. In this sense, the online aspect is providing an efficient distribution mechanism, replacing CDROMs or even printed manuals. In contrast, institutions of higher education offer their courses in quite a different form: In most cases, class cohorts are formed rather like traditional classes that start and end on specific days. These online classes are led by faculty members who most likely require participation from students on topics that are being covered, and discussions and exchanges of ideas among cohort members. A participant may seek help on a problem set or clarification of an assignment from classmates who are distant but online. This capability of student-to-student and studentto-faculty interaction, coupled with instant access to information resources worldwide on the Internet, plus the efficient distribution of class materials (readings, homework assignments, and possibly stored video lectures) distinguishes modern online education from older "distance education" models built around correspondence or television. 
In this modern version, basic technology requirements for students anywhere in the world are conventional personal computers with a broadband connection to the Internet. Students and faculty engage in classes using course management software [3], and classes are conducted "asynchronously," that is, there is no need for students and faculty to assemble at the same time, as in traditional classroom instruction. Indeed, course management systems have become ubiquitous in higher education, used for both online and on-ground asynchronous instruction. Synchronous software is sometimes employed for simultaneous voice and text discussions, often as an optional class activity. Newer devices like iPods are being employed in a number of instances, and even virtual environments such as Second Life [4] are quite widely seen in connection with corporate or specialized lecture-style environments. For institutions that offer for-credit courses and degrees, however, newer methods of teaching are mainly at an early, experimental stage.

The annual Sloan Consortium survey of online education [5] provides an information base for positioning the online modality as an important element of education. The study reports the responses of chief academic officers at 2500 degree-granting institutions of higher education to the online teaching and learning landscape (the response represents more than $50 \%$ of all such institutions in the United States). The most recent survey, published in 2008, reports that 3.94 million students enrolled in at least one online course for the fall semester of 2007 in a wide range of disciplines (see Fig. 1). Annual enrollment increases have averaged just below 20\% over the past 6 years of this study, leading to the result that today more than 20 to $25 \%$ of all students in U.S. colleges enroll in at least one online class. Many of these students are off-campus learners with a wide range of ages, work experience, and family circumstances; however, at a number of institutions, about half of the online enrollments are estimated to be full-time "traditional" students attracted to online courses for reasons of convenience or scheduling. Most are at public institutions - state universities, colleges, and community colleges—all of which offer at least some online education. Some of these institutions report large enrollments, for example, in the tens of thousands; community college enrollments alone account for about $50 \%$ of the 3.94 million students enrolled.

In contrast, only about half of the traditional private institutions provide any sort of for-credit online course offerings. Among those that do, however, are institutions such as Stanford and Johns Hopkins, both of which offer courses and some degree programs entirely online. Harvard and the University of California, Berkeley, also offer courses online, but mainly through their extension units; they offer no degree programs. Other elite schools, such as Princeton, Yale, and MIT, offer no online courses for credit or degree programs. In comparison, the enrollment at Pennsylvania State University's World Campus exceeds 20,000. The enrollment at the University of Massachusetts online unit (UMass Online) exceeds 35,000. Rio Salado Community College in Phoenix reports similar numbers. The University of Illinois, Springfield, a small institution, now has an online student population approximately equivalent to their on-campus enrollment. Overall, the highest growth rates are at community colleges and at for-profit organizations such as University of Phoenix, Kaplan, and Capella. It appears that, to this point, online education has not resulted in Noam's "dim circumstances" for the many institutions that have adopted online education. In fact, the fear that fewer faculty would be needed has been turned on its head: More faculty are being hired to service burgeoning online enrollments. Neither has online growth created a dim prognosis for highly endowed institutions, many of which have no online education program. It has, however, drawn the attention of other stakeholders, such as governments (both state and federal) and accreditors, now being forced to deal with an educational activity very different from traditional classroom teaching. 


\section{IMPACT ON STUDENTS}

A primary driver for online education is the presupposition of faculty and university administrators that a sizable population of potential learners exists-typically, working adults who wish to obtain college credit and credentials but who cannot do so because of time restraints imposed by work, family, community responsibilities, or lack of proximity to a suitable educational institution. Faculty members and institutions expected the asynchronicity and distance-independence of online education to be an answer for this population. Largely, this assumption has proven to be true. We have no accurate national profile, however, of the age of the "average" online students and their demographics, nor are those facts likely to emerge in the near future; no national profile of "traditional students" exists either, but some inferences are possible from individual institutions that collect data about online students.

The University of Central Florida, a large metropolitan university in Orlando, has developed an excellent, regularly updated database of its online students. Their analysis [6] contains some surprises: Of 115,000 students enrolled in their blended online courses in the seven-semester period from summer 2004 to summer 2006, nearly 80\% represented the so-called "millennial" generation (born after 1980); they dominated enrollments in lower- and upper-level undergraduate classes, and also in graduate classes. The remaining 20\% comprised earlier generations, including a small number from the "matures," born before 1946.

Are the several million students who have taken online courses satisfied with their learning experience, and have they had a high-quality learning experience? Is online learning a doorway to high quality education? These questions are difficult to answer because huge variances exist in instructors' teaching skills and experience, course organization, and in study materials for students. These elements provide variations similar to the differences in educational outcomes found in traditional classrooms. From data provided by individual institutions, we do see quite uniformly that grades and completion rates for welldesigned online courses taught by experienced instructors tend to result in equivalent outcomes for both online and traditional students [7-9]. In most cases, therefore, it appears that online students receive an education equivalent in quality to what they would receive in traditional classes, and their drop-out rates appear to be about the same.

\section{IMPACT ON FACULTY}

The emergence of online education has had an impact on faculty as well, certainly on those who teach classes online, but also on those who are experimenting with Web-based elements blended into traditional classes. Eventually, we expect Internet use in courses to envelop all faculty, as blended approaches become the norm for college courses over the coming 5 to 10 years. In the United States, about 1.3 million faculty work in degree-granting postsecondary institutions; of those, about half are full time [10]. The 3.94 million students taught online represent about $22 \%$ of the estimated total national student population. If the number of faculty is roughly proportional to the students enrolled, then approximately 300,000 faculty engage in online teaching in the United States today. Of those, some estimates place more than 100,000 in the adjunct category [11]; that is, faculty who are not permanent employees of an institution. A commonly held misconception is that online faculty are all or mostly adjuncts. It would likely be fair to estimate that adjunct and permanent faculty of diverse types mirror the full-time/part-time proportions found in face-to-face teaching.

A number of institutions [12-14] conduct surveys of faculty satisfaction factors and attitudes toward online education. Across institutions, the results tend to be quite similar. Almost unanimously, online instructors assert that although preparing and teaching online courses is more time-intensive than 
classroom teaching, they plan to continue teaching in that modality for a variety of reasons: the flexibility of "anyplace, anytime teaching" for themselves and for their students, opportunity for professional growth, the option of teaching from home, and interactivity with students, which they report is of higher quality than classroom discussion. These faculty are also motivated by a strong conviction that the work they are doing is important to students who need flexible access to education, although they point out that online students need to be more self disciplined. In addition to the data reported by a handful of institutions, a completed national survey of nearly 10,000 faculty members from a recent diverse sampling of 60 campuses by Seaman and Allen [15] confirms these conclusions. Economic issues also come into play for some faculty. Commonly, an on-ground itinerant faculty member who travels to three campuses a week may absorb sizeable transportation time and costs. Online instruction brightens this picture. By teaching online, those faculty can accommodate an additional course or two-a substantial bonus for an adjunct professor earning a living by teaching.

Because the professoriate is aging, not all faculty members wish to acquire the skills needed to engage with millennial students who befuddle them with wikis, blogs, Web casts, virtual worlds, and course management systems. To ease their transition to this new teaching agenda, many institutions provide support for instructors to transfer their courses to the online modality. Faculty members who subscribe to the mantra "I can't teach them if I can't look them in the eye" will slowly become obsolete except in some exclusive colleges. The millennials are changing the way teaching and learning must be approached. Mobile learning with podcasts, text messaging, and Virtual worlds will be the future norm, giving faculty new tools through which to extend and enhance the educational experience.

\section{GOVERNMENTS, REGULATION, AND ACCREDITORS}

Federal and state governments involve themselves in higher education for different reasons. The federal government is involved through its role in federal grant and loan programs such as Pell grants and the Federal Family Education Loan Program; state governments view their role to be licensing and accrediting institutions of higher education within their state boundaries, providing financial support for public institutions in their state, and, in an increasing number of cases, offering their own student aid programs. The states have traditionally asserted a right to impose rules and regulations on institutions that are located on their soil; that is, those with a "physical presence" within their state boundaries.

The role of the federal government in postsecondary education has largely been defined by the Higher Education Act of 1965 (HEA). Responsibility for administration of this law has fallen to the U.S. Department of Education, which delegates key functions and policies to other stakeholders, such as accreditation agencies and the colleges and universities themselves. The recent reauthorization of the HEA, the Higher Education Opportunity Act of 2008 [16], contains several specific provisions that indicate that the federal government is increasingly taking into account the importance of online education as an element in U.S. higher education.

Before 1996, the Department of Education treated asynchronous online learning as conventional correspondence study, and this resulted in a reduction of the federal financial aid available to individual online learners by more than half. In that year, the HEA was amended to separate "courses offered through telecommunications" from correspondence and to treat students enrolled in such courses as equivalent to those attending classes in person. However, reflecting a continuing unease with online learning, Congress limited the applicability of this provision to institutions that still offered a majority their courses in a conventional (that is, face to face) mode. Congress subsequently enacted, and the Department of Education implemented, the Distance Education Demonstration Project that allowed a limited number of colleges to offer more than $50 \%$ of their courses online, which opened the door to a 
few entirely online institutions. The 50\% rule was rescinded in 2006, but the latest amendment to the HEA makes it clear that there is still residual discomfort with asynchronous learning. Although there is no longer any restriction on the ability of a university to offer its programs entirely online, it may only do so if it has secured specific approval from its accrediting commission [17], provided that the accrediting commission has itself been determined by the Department of Education to be qualified to evaluate an institution's distance learning offerings. One provision of the new law bears specifically on asynchronous learning. Institutions offering online programs must establish "processes through which the institution establishes that the student who registers in a distance education or correspondence education course or program is the same student who participates in and completes the program and receives the academic credit" [18]. Congress has assigned responsibility for enforcing this requirement not to the Department of Education but to the accrediting commissions. Other issues in the law directly affecting online delivery of courses are covered in an excellent report from Dow Lohnes PLLC [19].

Although both Congress and the Department of Education have shown increasing interest in online learning, it is the individual states that have been most involved in the regulation of online education. In a recent survey [19], an increasing number of states are asserting what some would consider novel interpretations of "physical presence." For instance, it is common practice for online course providers to require a remote student to take a final examination under the supervision of a proctor, for example, a librarian or a local government official, or to meet with a discussion group of fellow students. Although both of these approaches are desirable adjuncts to effective online learning programs, some states are now asserting that these activities constitute a "physical presence" sufficient to require the institution to be licensed by the state in which the students reside. Indeed, some states have gone well beyond this, asserting that the mere fact of delivering the online program across its borders and enrolling its citizens is sufficient to require an institution to submit to its regulation. These examples show that both federal and state governments and accreditors are clearly being affected by the emerging world of online and blended instruction and that they are experimenting with ways to deal with this new world, particularly in balancing the need to protect consumers against unscrupulous purveyors of substandard programs and yet not interfere with the growth of this essential component of postsecondary education. The complexity of these issues is multiplied many times over when one considers the implications of online learning crossing international boundaries. Governments and quasi public bodies charged with oversight of postsecondary education will need to develop considerably more sophistication as colleges and universities, both within the United States and globally, expand the scope and reach of their online programs.

\section{INSTITUTIONS}

Finally, we turn to the question, Are traditional institutions of education facing a threat from the growth and increasing validation of online instruction? There is little evidence today to suggest much of a threat. For-profit institutions such as Phoenix, Kaplan, Capella, and Jones are successful, and their growth rates exceed those of the online programs in traditional institutions. They are clearly meeting a need. However, overall, online enrollments are still dominated by traditional institutions, and certainly all the public institutions and a number of private ones have acquired the skills, infrastructure, and faculty acceptance to allow them to compete effectively and to continue competing. Some evidence indicates that online enrollments in many of these institutions appear to be leveling off, and that is most likely an indication of internal decisions to maintain some arrived-at "balance" between classroom instruction and blended instruction and some overall ceiling on enrollments. Traditional institutions, especially public ones, do have some substantial advantages over for-profit institutions like the University of Phoenix, although it is clear that the distinction is blurring as the most successful for-profit institutions increase their focus on academic performance and as "traditional" schools learn how to compete more effectively in the marketplace, particularly in the context of leveraging name recognition at a local and regional level and, 
in some cases, at a national and international level, as well as the ability of public institutions in particular to offer considerably lower prices.

The institutions that have adopted online offerings on a large scale appear to be well positioned to avoid the "dim" future foreseen by Noam. They are adapting and can easily continue to adapt and prosper.

The leadership elements-presidents or chancellors-of the public institutions with large online enrollments are recognizing the strategic advantages of online and blended education and hence are treating this form of education as a strategic priority. Our discussion with the presidents or chancellors of Pennsylvania State University, University of Massachusetts, University of Central Florida, University of Southern Maine, University of Illinois, Springfield, and Rio Salado Community College indicate clearly that they are including online instruction as a strategic asset that is integral to the planning activities of their institutions. So, for instance, online possibilities can affect strategic decisions directed at addressing problems such as insufficient classroom space or reaching new markets (possibly including international students) to provide greater access to education. Some institutions are seeing strategic possibilities in online education to retard, and maybe reverse, the trend toward ever-lengthening time for a student to acquire a degree. Others are seeing possibilities for course-sharing and faculty sharing among geographically separated institutions and for strengthening relationships among community colleges and baccalaureate and graduate institutions.

A number of select, highly endowed elite institutions do not see offering credit-bearing online courses and degree programs as a high priority, although they might make available free course materials, even the content of complete courses, as noted earlier. For these institutions, online teaching and credit-bearing offerings are not a necessary strategic or competitive tool. They do not appear to believe that their futures have been dimmed at all by the appearance of online education on a large scale at other institutions. These institutions, however, along with all others, will adopt and be affected by the more recent growth of blended education.

What of the less highly endowed institutions that have chosen not to involve themselves in online education? For these institutions, it appears the future may be more turbulent, perhaps even dim. Their income is largely dependent on students, and that supply of students may follow a downward path as online options proliferate from other, often distant, institutions. Finally, a quick look at the situation outside the United States indicates that the story is less promising, even in Canada. In Europe, there have been a number of high-profile failures of online universities and a larger number of initiatives that never reached their full potential. (There have been failures in the United States, too, but few compared with the successes.) These include the UK e-University [20], the Scottish Interactive University [21], the Dutch Digital University [22], and the NHS University [23]. Several others have dwindled more quietly, with no news emanating in English on the Web. Many reasons have been advanced for the far greater success of online education in the United States, greater than the higher gross domestic product alone should justify. Reasons suggested include the greater "travel to study" distances, a more "can do" culture, and more acceptance of private universities, both nonprofit and for-profit. Yet, in many European countries, initiatives continue-the Telematic Universities in Italy, the Campus Numériques in France, and the Swiss Virtual Campus collaboration (this latter example is coming to a planned end, not a failure). There is also an undercurrent of lower-profile but sound initiatives such as the private Hibernia College in Ireland; the U.K. universities of Derby, Leicester, Middlesex, Staffordshire, and Ulster; the collaboration of Liverpool University with Laureate Education Inc. to deliver master's programs; and, in addition, the various open universities across Europe rapidly reengineering themselves from distance learning to online learning. Similar initiatives have arisen in the community college sector in several other countries and regions such as England, Wales, Bavaria, and Norway. So, although many U.S. providers are looking 
beyond the border and seeing very little competition, the global situation is likely to get considerably tougher in years to come, when competition for online students who live anywhere becomes as fierce as it is for traditional campus students.

\section{Penetration rates of Online Programs by Discipline - By total Enrollment - Fall 2007}

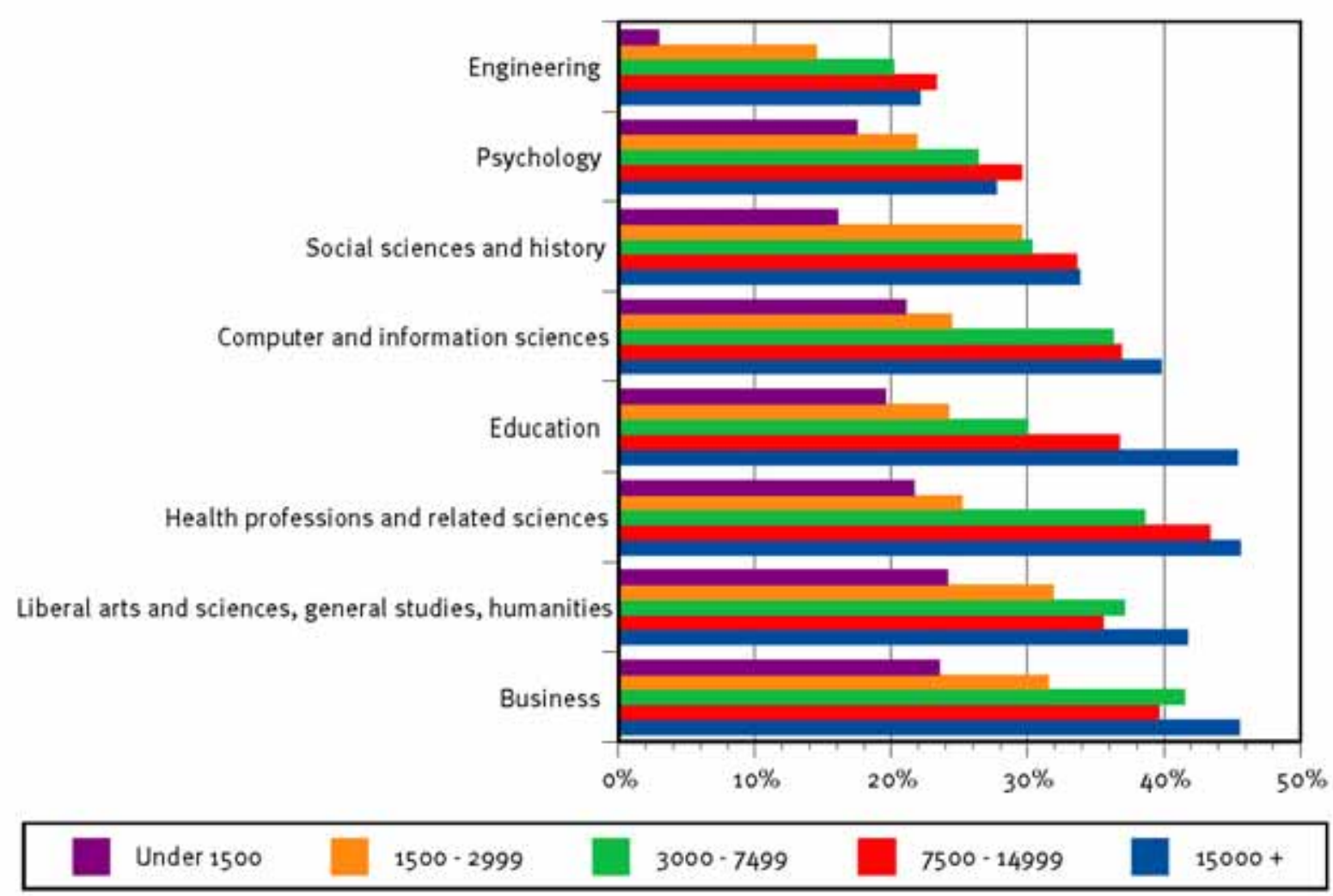

Fig. 1. Penetration of online programs by discipline and total enrollment, fall 2007. Data represent the results of the most recent Sloan Consortium national survey of all active, degree-granting institutions of higher education in the United States that are open to the public [24]. "Penetration" refers to the fraction of all online degree programs offered by such institutions as a fraction of all degree programs in that discipline. [Reproduced by permission of the Sloan Consortium]

\section{REFERENCES AND NOTES}

1. E. M. Noam, Science 270, 247 (1995).

2. See, e.g.; http://ocw.mit.edu/OcwWeb/web/home/home/index.htm.

3. See, e.g.; http://en.wikipedia.org/wiki/Learning_management_system.

4. Second Life; http://secondlife.com.

5. See www.sloanconsortium.org/publications/survey/index.asp.

6. C. Dziuban, P. Moskal, Educause Q. 24, 60 (2001).

7. J. Hartman, C. Dziuban, P. Moskal, in Online Education: Proceedings of the Sloan Summer Workshop on Asynchronous Learning Networks, J. R. Bourne, J. C. Moore, Eds. (Sloan Consortium, Needham, MA, 1999), pp. 155-179.

8. J. Fjermestad, S. Hiltz, Y. Zhang, in Learning Together Online, S. Hiltz and R. Goldman, Eds. (Lawrence Erlbaum, NY, 2005), pp. 39-80

9. R. Ragan, J. Kleoppel, J. Asynchronous Learn. Networks 8, 15 (2008). 
10. National Center for Education Statistics, Digest of Education Statistics, 2007; http://nces.ed.gov/programs/digest/d07.

11. A. Finder, "Adjuncts outnumber tenured faculty on U.S. campuses," International Herald Tribune, 20 November 2007; www.iht.com/articles/2007/11/20/america/college.php.

12. A. Pickett, Faculty Development Process, Sloan-C Effective Practice; http://sloanconsortium.org/node/347.

13. E. Kashy, M. Thoennessen, Y. Tsai, G. Albertelli II, J. Asynchronous Learn. Networks 4, 231 (2000).

14. P. Shea, J. Asynchronous Learn. Networks 11, 73 (2007).

15. NASULGC-Sloan National Commission on Online Learning, Benchmarking Study: Preliminary Findings (2008); available at www.sloanconsortium.org/publications/survey/nasgulc-prelim.

16. Higher Education Opportunity Act, P.L. 110-315, 14 August 2008.

17. Accrediting commissions are nongovernmental agencies that conduct independent assessments of institutional quality and integrity. Certain accrediting commissions have sought and are recognized by the U.S. Secretary of Education as being "reliable" arbiters of institutional quality, and that approval is a requirement for institutional participation in the federal student financial aid programs.

18. See [16], section 495, paragraph 1.

19. Dow Lohnes; www.dowlohnes.com/postsecondary/accreditation.

20. P. Bacsich, Lessons to be learned from the failure of the UK e-University (2005); www.odlaa.org/events/2005conf/ref/ODLAA2005bacsich.pdf.

21. Megatrends in e-learning provision: E-learning initiatives which were discontinued because they failed to reach targeted goal: The Scottish Interactive University (2002); http://nettskolen.nki.no/in_english/megatrends/Discontinued/. Discontinued_ScottishInteractiveUniversity.pdf

22. See www.du.nl for a cryptic closure message (in Dutch).

23. D. McLeod, "NHS University axed," The Guardian, 30 November 2004; www.guardian.co.uk/education/2004/nov/30/highereducation.uk3.

24. I. E. Allen, J. Seaman, Staying the Course: Online Education in the United States, 2008 (Sloan Consortium, Needham, MA, 2008); www.sloanconsortium.org/ publications/survey/pdf/staying_the_course.pdf.

25. The authors are grateful for helpful critiques from C. Dziuban at University of Central Florida and M. Goldstein of Dow Lohnes PLLC. 